University of Nebraska - Lincoln

DigitalCommons@University of Nebraska - Lincoln

$1-2017$

\title{
A Systematic Review and Secondary Data Analysis of the Interactions between the Serotonin Transporter 5-HTTLPR Polymorphism and Environmental and Psychological Factors in Eating Disorders
}

Vanja Rozenblat

Deborah Ong

Matthew Fuller-Tyszkiewicz

Kirsti Akkermann

David Collier

See next page for additional authors

Follow this and additional works at: https://digitalcommons.unl.edu/psychfacpub

Part of the Genetics Commons, and the Psychology Commons

This Article is brought to you for free and open access by the Psychology, Department of at

DigitalCommons@University of Nebraska - Lincoln. It has been accepted for inclusion in Faculty Publications, Department of Psychology by an authorized administrator of DigitalCommons@University of Nebraska - Lincoln. 


\section{Authors}

Vanja Rozenblat, Deborah Ong, Matthew Fuller-Tyszkiewicz, Kirsti Akkermann, David Collier, Rutger C. M. E. Engels, Fernando Fernandez-Aranda, Jaanus Harro, Judith R. Homberg, Andreas Karwautz, Evelyn Kiive, Kelly K. Klump, Sarah E. Racine, Jodie Richardson, Howard Steiger, Scott F. Stoltenberg, Tatjana van Strien, Gudrun Wagner, Janet Treasure, and Isabel Krug 
Published in Journal of Psychiatric Research 84 (January 2017), pp. 62-72;

doi: 10.1016/j.jpsychires.2016.09.023

Copyright (C) 2016 Elsevier Ltd. Used by permission.

Submitted March 1, 2016; revised September 22, 2016; accepted September 23, 2016; published online September 24, 2016.

\section{A Systematic Review and Secondary Data Analysis of the Interactions between the Serotonin Transporter 5-HTTLPR Polymorphism and Environmental and Psychological Factors in Eating Disorders}

Vanja Rozenblat, ${ }^{1}$ Deborah Ong, ${ }^{1}$ Matthew Fuller-Tyszkiewicz, ${ }^{2}$

Kirsti Akkermann, ${ }^{3}$ David Collier, ${ }^{4}$ Rutger C. M. E. Engels, ${ }^{5}$

Fernando Fernandez-Aranda ${ }^{6,7}$ Jaanus Harro, ${ }^{3}$ Judith R. Homberg, ${ }^{8}$

Andreas Karwautz, ${ }^{9}$ Evelyn Kiive, ${ }^{3}$ Kelly L. Klump, ${ }^{10}$ Christine L. Larson, ${ }^{11}$

Sarah E. Racine, ${ }^{10}$ Jodie Richardson, ${ }^{12,13}$ Howard Steiger ${ }^{12,13}$

Scott F. Stoltenberg, ${ }^{14}$ Tatjana van Strien, ${ }^{5}$ Gudrun Wagner, ${ }^{9}$

Janet Treasure, ${ }^{15}$ and Isabel Krug ${ }^{1}$

1. Department of Psychological Sciences, University of Melbourne, Melbourne, Victoria, Australia

2. School of Psychology, Deakin University, Geelong, Victoria, Australia

3. Department of Psychology, Estonian Centre of Behavioural and Health Sciences, University of Tartu, Tartu, Estonia

4. Social, Genetic, and Developmental Psychiatry Research Centre, Institute of Psychiatry, King's College, London, United Kingdom

5. Behavioural Science Institute, Radboud University Nijmegen, Nijmegen, The Netherlands

6. Department of Psychiatry, University Hospital of Bellvitge - IDIBELL, Barcelona, Spain 
7. CIBER Fisiopatologia Obesidad y Nutricion (CIBERobn), Instituto Salud Carlos III, Madrid, Spain

8. Donders Institute for Brain, Cognition, and Behaviour, Centre for Neuroscience, Radboud University Medical Centre, Department of Cognitive Neuroscience, Nijmegen, The Netherlands

9. Department of Child and Adolescent Psychiatry, Medical University of Vienna, Vienna, Austria

10. Department of Psychology, Michigan State University, East Lansing, Michigan, USA

11. Department of Psychology, University of Wisconsin-Milwaukee, Milwaukee, Wisconsin, USA

12. Eating Disorders Continuum, Douglas Institute, Montreal, Quebec, Canada

13. Psychiatry Department, McGill University, Montreal, Quebec, Canada

14. Department of Psychology, University of Nebraska-Lincoln, Lincoln, Nebraska, USA

15. The Institute of Psychiatry, Psychology, and Neuroscience, King's College, London, United Kingdom

Corresponding author - Vanja Rozenblat, School of Psychological Sciences, University of Melbourne, Level 12 Redmond Barry Building, Parkville 3010, Australia, email vanja@rozenblat.net

\begin{abstract}
Objectives: To summarize and synthesize the growing gene $\times$ environment $(G \times E)$ research investigating the promoter region of the serotonin transporter gene (5-HTTLPR) in the eating disorders (ED) field, and overcome the common limitation of low sample size, by undertaking a systematic review followed by a secondary data meta-analysis of studies identified by the review. Method: A systematic review of articles using PsycINFO, PubMed, and EMBASE was undertaken to identify studies investigating the interaction between 5-HTTLPR and an environmental or psychological factor, with an ED-related outcome variable. Seven studies were identified by the systematic review, with complete data sets of five community $(n=1,750,64.5 \%$ female) and two clinical $(n=426,100 \%$ female) samples combined to perform four secondary-data analyses: 5-HTTLPR $\times$ Traumatic Life Events to predict ED status $(n=909), 5-H T T L P R \times$ Sexual and Physical Abuse to predict bulimic symptoms $(n=1,097), 5$-HTTLPR $\times$ Depression to predict bulimic symptoms $(n=1,256)$, and 5HTTLPR $\times$ Impulsiveness to predict disordered eating $(n=1,149)$. Results: Under a multiplicative model, the low function (s) allele of 5-HTTLPR interacted with traumatic life events and experiencing both sexual and physical abuse (but not only one) to predict increased likelihood of an ED and bulimic symptoms, respectively. However, under an additive model there was also an interaction between sexual and physical abuse considered independently and 5-HTTLPR, and no interaction with traumatic life events. No other $\mathrm{G} \times \mathrm{E}$ interactions were significant. Conclusion: Early promising results should be followed-up with continued cross-institutional collaboration in order to achieve the large sample sizes necessary for genetic research.
\end{abstract}

Keywords: eating disorders, gene-environment interaction, 5-HTTLPR, meta-analysis, systematic review, bulimia nervosa

\title{
1. Introduction
}

Over the past decade, etiological models of eating disorders (EDs) have increasingly acknowledged the role of genetics, with twin studies estimating a notable heritable component (approximately 40-60\%; Bulik et al., 2006, 2010; Fairweather-Schmidt and Wade, 2015; Trace et al., 2013). Investigations so far have not consistently identified specific candidate genes associated with increased ED risk, suggesting that hereditary factors in EDs may not operate via simple genetic association (Trace et al., 2013). Hence, studies are now increasingly examining whether environmental factors moderate the influence of candidate genes 
on risk for pathological eating behavior. Gene $\times$ environment $(G \times E)$ interaction research in the ED field is still relatively novel, with early studies identifying potential candidate genes associated with ED risk under specific environmental conditions (e.g., history of abuse; Steiger et al., 2012). In anticipation of the increased popularity of this research focus, it is timely to evaluate the current state of evidence and to highlight existing limitations, in order to guide the direction and methods of future $G \times E$ studies in eating pathology.

Previous research examining genetic influences on eating pathology has primarily focused on genes in the serotonin and dopamine systems linked to functions relevant to EDs, including appetite, mood, and reward sensitivity (e.g., SLC6A4, HTR2A, DRD2, DRD4, DAT1, and COMT; see Culbert et al., 2015, and Trace et al., 2013, for a review). Direct genetic association studies have not provided a clear picture of the links between specific genes and EDs or disordered eating symptoms, with many initial significant findings failing to achieve consistent replication (see Calati et al., 2011; Culbert et al., 2015; Lee and Lin, 2010; Scherag et al., 2010; Trace et al., 2013).

One reason for a lack of direct association between allele frequency and ED risk may be that this relationship is moderated by environmental factors. Under the diathesis-stress model of $\mathrm{G} \times \mathrm{E}$ interactions, individuals carrying a "risk" allele may be more susceptible to EDs when exposed to environmental stressors but show no differences in outcome in the absence of challenging environmental circumstances, compared to those without the risky genotype (Caspi et al., 2003; Monroe and Simons, 1991). The role of $\mathrm{G} \times \mathrm{E}$ interactions in psychology has gained increasing attention since Caspi et al. (2003) found that stressful life events increased susceptibility to depression for those with one or two copies of the short (s) allele of the serotonin transporter gene (5-HTTLPR polymorphism).

Studies have since largely focused on 5-HTTLPR because of its biological relevance to psychiatric disorders (with the s-allele reducing serotonin transporter transcription efficiency; Heils et al., 1996), and early significant findings in the depression literature (Karg et al., 2011). Despite substantial research investigating $\mathrm{G} \times \mathrm{E}$ interactions with 5-HTTLPR and other polymorphisms, many studies are limited by small sample size, and replicability remains a major issue (see Duncan et al., 2014 for a review; Risch et al., 2009). Furthermore, most studies to date failed to control for confounding influences on the $G \times E$ interaction by not including all required covariate $\times$ gene and covariate $\times$ environment contrast terms in the regression model (Keller, 2014). Studies examining case-control samples have also tended to evaluate the $\mathrm{G} \times \mathrm{E}$ effect using logistic regression and have thus tested departures from a multiplicative model of interaction, which is believed to be less biologically plausible than an additive model (Rothman, 1976; Rothman and Greenland, 1998).

$\mathrm{G} \times \mathrm{E}$ studies of candidate genes in eating pathology have been scarce. A recent review by Culbert et al. (2015) highlighted the heterogeneity of candidate $G \times E$ research in eating pathology. Their investigation identified five studies examining candidate $G \times E$ interactions with eating pathology outcome variables. Two studies reported a significant $\mathrm{G} \times \mathrm{E}$ interaction for 5-HTTLPR (Karwautz et al., 2011; parenting styles; Akkermann et al., 2012; traumatic life events), while one study investigating a psychological factor did not (Racine et al., 2009; impulsivity). The two remaining studies examined other genes (NR3C1 $\times$ childhood abuse, Steiger et al., 2011; BDNF × restricted food intake; Akkermann et al., 2011), finding significant interactions to predict bulimia nervosa $(\mathrm{BN})$ spectrum pathology. This 
paper presents a good start in summarizing candidate $\mathrm{G} \times \mathrm{E}$ literature in eating disorders (although it was not a systematic review and thus omitted several studies, e.g., Stoltenberg et al., 2012; van Strien et al., 2010), and reflects the growing focus on gene $\times$ environment interactions in the eating disorders field.

While candidate $G \times E$ research in eating pathology is still in its infancy, it is not premature to consider how to best utilize academic resources to avoid the pitfalls $G \times E$ research has faced in other fields, such as lack of consistent replication and small sample sizes (Dick et al., 2015). This will aid greater accuracy in $G \times E$ findings, which is a vital step in increasing understanding of how individual differences at the genetic level can influence susceptibility to eating pathology. In the depression field, a protocol for a collaborative metaanalysis to achieve these aims has been published $(N=33,761)$, with authors aiming to reanalyze their data using a standardized analysis script to increase consistency of analytic methods and phenotypic definitions (Culverhouse et al., 2013). Future collaborations could integrate complete datasets for combined re-analysis rather than relying on summary statistics. No such study has been undertaken in the ED field so far.

Thus, the present study aims to provide a systematic, detailed overview and re-analysis of current $\mathrm{G} \times \mathrm{E}$ studies investigating 5-HTTLPR in eating pathology, to clarify the current state of knowledge and to encourage future research to build upon this via continued focus on replication of published findings and multi-institute collaborations to achieve larger sample sizes. Specifically, it will examine, via a systematic review, existing studies that have analyzed how the interaction between 5-HTTLPR and an environmental or psychological factor influences ED status or subthreshold ED symptomatology. Secondary data meta-analyses to re-analyze $\mathrm{G} \times \mathrm{E}$ interactions using larger sample sizes with appropriate control of confounding variables as per Keller (2014) will then be performed by aggregating the results of three or more existing studies in a series of smaller analyses. Each analysis will be tested according to the multiplicative model of interaction, for consistency with prior research, and also according to the additive model of interaction, because of the possibility that this better represents and may be more sensitive to identifying gene $\times$ environment interactions. This study will be reported according to PRISMA guidelines where applicable (Moher et al., 2010).

\section{Systematic review}

\subsection{Inclusion criteria and search strategy}

The databases PsycINFO, PubMed, and EMBASE were searched through to January 2016 by two authors (V.R. and D.O) using the search terms ("eating disorder" or "disordered eating" or "anorexi" $\mathrm{i}^{* \prime}$ or "bulimi" or "binge eating" or "emotional eating" or "dietary restraint") + ("gene environment interaction" or "gene" or "allele"), limited to "human only" and English language. Inclusion criteria included testing an interaction between 5-HTTLPR and an environmental or psychological factor, with eating pathology as the outcome variable. Eating pathology included a clinical-level diagnosis or a measure of disordered eating (e.g., dieting, body dissatisfaction). Studies examining body mass index (BMI) or weight

gain as the outcome variable, or examining twin samples rather than candidate genes, were 
excluded to maintain a focused investigation of 5-HTTLPR. While not technically an "environmental" factor, psychological factors were included in the search as in many cases such variables are implicated in the aetiology of EDs and may influence how a genetic variant modifies risk for EDs (e.g., impulsivity in BN, Steiger et al., 2005). Indeed, many studies have investigated psychological factors within a $\mathrm{G} \times \mathrm{E}$ framework both in the ED literature (Akkermann et al., 2011; Racine et al., 2009; Mata and Gotlib, 2011; van Strien et al., 2010) and in other psychopathologies (Lu et al., 2011; Mandelli et al., 2009; Wang et al., 2013). Results were limited to published studies. A total of 1,353 papers were initially identified (701 duplicates), with 35 selected for closer reading. Of these, 7 papers met criteria for the systematic review, with a summary provided in Figure 1.

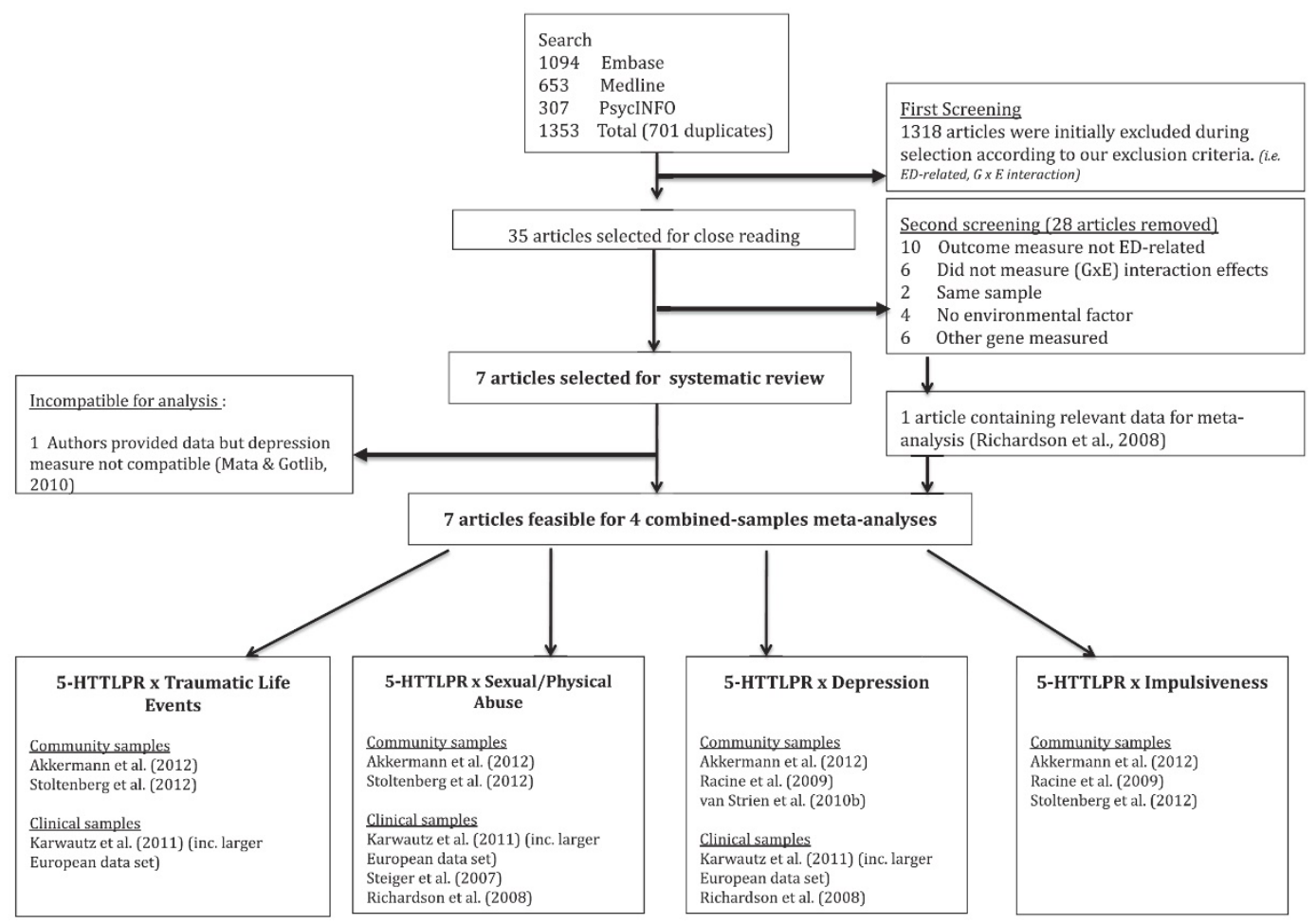

Figure 1. Flow chart depicting selection of papers for systematic review and secondary data meta-analyses based on analysis of 5-HTTLPR $\times$ environment interaction with an ED-related outcome variable.

\subsection{Quality appraisal}

Quality of each study in the systematic review was evaluated using a framework by Downs and Black (1998). As this tool was created to assess clinical trials, criteria were adapted to evaluate $\mathrm{G} \times$ E research in eating disorders, with 14 nonapplicable criteria excluded. A brief description of the items is presented, with notes in parentheses detailing changes in their current application: (1) Clear description of the hypothesis/aim/objectives; (2) Clear description of main outcomes in introduction/method; (3) Participant characteristics clearly 
described (as appropriate for $\mathrm{G} \times \mathrm{E}$ and ED research); (4) Clear description of main findings; (5) Characteristics of participants lost to follow-up described; (6) Exact probability values reported (or confidence intervals included); (7) Participants representative of population (including clinical, but not convenience samples); (8) Any "data-dredging" explicitly noted; (9) Appropriate statistical tests used; (10) Main outcome measures valid and reliable; (11) Participants in different groups (if case-control study) recruited contemporaneously; (12) Adequate adjustment for (potential) confounding variables (e.g., BMI; according to Keller (2014), this requires inclusion of all covariate $\times$ gene and covariate $\times$ environment interaction terms in the model); and (13) Sufficient power (to detect a G $\times \mathrm{E}$ interaction, as guided by Duncan and Keller, 2011).

Studies were evaluated independently by two coders, V. R. and D. O., and cross-checked for consistency. Discrepancies were discussed amongst the raters with a third author (I. K.) consulted where necessary. Another author with particular expertise in statistical methods in psychology (M. F. T.) additionally evaluated criterion 9. To avoid biases or conflicts of interest, no other coauthors provided input to the evaluation.

Table 1 presents results of the quality evaluation. Discrepancy between coders was lower than 5\%. The evaluation found that studies largely adopted valid and reliable methods with good reporting of results. The main issues pertained to insufficient power to detect the small-to-medium effect sizes likely involved in $\mathrm{G} \times \mathrm{E}$ interactions (Duncan and Keller, 2011), and that no study properly controlled for potential confounds on the interaction effect by including covariate $\times$ gene and covariate $\times$ environment interaction terms (Keller, 2014). Some studies tested three-category polymorphic groupings using crossproduct terms in regression models, which was recently suggested to be statistically flawed due to the possibility of both false positive and negative results (Aliev et al., 2014). Nonetheless, the studies present promising initial findings and constitute good building blocks for continued $G \times E$ analyses in the field.

Table 1. Downs and Black (1998) Checklist for Methodological Quality, adapted to evaluate studies identified in a systematic review of the role of 5-HTTLPR $\times$ environment interactions in risk for eating pathology

\begin{tabular}{lccccccccccccc}
\hline Study & 1 & 2 & 3 & 4 & 5 & 6 & 7 & 8 & 9 & 10 & 11 & 12 & 13 \\
\hline Steiger et al. & 1 & 1 & 1 & 1 & N/A & 1 & 1 & 1 & 1 & 1 & N/A & 0 & 0 \\
Racine et al. & 1 & 1 & 1 & 1 & $\mathrm{X}$ & 1 & 0 & 1 & 1 & 1 & N/A & 0 & 0 \\
Mata \& Gotlib & 1 & 1 & 1 & 1 & 0 & 1 & 0 & 1 & 1 & 1 & N/A & 0 & 0 \\
van Strien et al. & 1 & 1 & 1 & 1 & 1 & 0 & 1 & 1 & 1 & 1 & N/A & 0 & 0 \\
Karwautz et al. & 1 & 1 & 1 & 1 & N/A & 1 & 1 & 1 & 1 & 1 & 1 & 0 & 0 \\
Akkermann et al. & 1 & 1 & 1 & 1 & 0 & 1 & 1 & 1 & 1 & 1 & N/A & 0 & 0 \\
Stoltenberg et al. & 1 & 1 & 1 & 1 & N/A & 1 & 0 & 1 & 1 & 1 & N/A & 0 & 0
\end{tabular}

$1=$ Criteria met, $0=$ Criteria not met, $X=$ Unable to determine, $N / A=$ Criteria not applicable. A description of each item is provided under the heading Quality Appraisal in the Method section.

\subsection{Summary of findings}

The systematic review identified 7 studies (see Table 2). Samples were from North American or European countries and $n$ varied from 50 to 584. Participants were mainly adolescents and young adults, with mean age spanning from 13.4 years to 25.6 years. Five studies 
investigated community samples (total $N=2017,78.0 \%$ female), with two of these studies investigating mixed gender samples. Two studies examined clinical ED patients $(N=348$, $100 \%$ female), with one of these a discordant sister-pair sample $(N=128$ controls, $100 \%$ female).

Three studies found a significant 5-HTTLPR $\times$ Traumatic Life Events interaction, although each predicted a different ED pathology; two disordered eating (Akkermann et al., 2012 - EDI-2 Bulimia subscale only; Stoltenberg et al., 2012 - EAT-26 total score) and one Anorexia Nervosa (AN) diagnosis (Karwautz et al., 2011). Notably, unlike in Akkermann et al. (2012) and Stoltenberg et al. (2012), Karwautz et al. (2011) found an interaction only when analyzing risky parenting styles and not for broader traumatic life events. One study found a significant sexual abuse $\times$ 5-HTTLPR interaction (Akkermann et al., 2012, predicting EDI-2 Bulimia and Drive for Thinness scales), while the other did not (Steiger et al., 2007; predicting BN-spectrum clinical diagnosis). Neither study reported a significant physical abuse $\times$ 5-HTTLPR interaction. Mata and Gotlib (2011) and van Strien et al. (2010) both reported a significant depression $\times 5$-HTTLPR interaction in predicting overeating and emotional eating, respectively, although this effect was only for the s/s genotype in the former study. Racine et al. (2009) found no interaction between 5-HTTLPR or HTR2A (T102C polymorphism) and impulsivity or dietary restraint in predicting binge eating or emotional eating symptoms.

\begin{tabular}{|c|c|c|c|c|c|c|c|}
\hline Author (year) & $\begin{array}{l}\text { Total no. of } \\
\text { participants } \\
\text { (no. women) }\end{array}$ & $\begin{array}{l}\text { Mean age, } \\
\text { yrs (SD) }\end{array}$ & $\begin{array}{l}\text { Clinical } \\
\text { sample }\end{array}$ & $\begin{array}{c}\text { 5-HTTLPR } \\
\text { genotype } \\
\%\end{array}$ & $\begin{array}{l}\text { Outcome } \\
\text { (measures) }\end{array}$ & $\begin{array}{l}\text { Environmental } \\
\text { factor }\end{array}$ & Results \\
\hline \multicolumn{8}{|c|}{ LL LS SS } \\
\hline Steiger et al. (2007) & $92(92)$ & $25.4(6.4)$ & $\mathrm{BN}$ & 344720 & $\begin{array}{l}\text { BN (EDE, EAT- } \\
\text { 26, DSMIV } \\
\text { diagnosis) }\end{array}$ & $\begin{array}{c}\text { Childhood } \\
\text { sexual/physical } \\
\text { abuse, (CTI) }\end{array}$ & $\begin{array}{l}\text { No significant } \\
\text { interactions }\end{array}$ \\
\hline Racine et al. (2009) & $344(344)$ & $19(1.4)$ & No & 275617 & $\begin{array}{c}\text { Binge eating } \\
\text { (MEBS), } \\
\text { Emotional } \\
\text { eating (DEBQ) }\end{array}$ & $\begin{array}{c}\text { Impulsivity } \\
\text { (Barratt } \\
\text { Impulsiveness } \\
\text { Scale) } \\
\text { Dietary } \\
\text { restraint } \\
\text { (EDEQ/ DEBQ } \\
\text { composite) }\end{array}$ & $\begin{array}{l}\text { No significant } \\
\text { interactions }\end{array}$ \\
\hline Mata and Gotlib (2011) & $50(50)$ & $13.9(1.9)$ & No & 284428 & $\begin{array}{l}\text { Overeating } \\
\text { (EDI-C) }\end{array}$ & $\begin{array}{l}\text { Depression } \\
\quad(\mathrm{CDI})\end{array}$ & $\begin{array}{l}\text { Interaction } \\
\text { between s/s (but } \\
\text { not s/l) genotype } \\
\text { and depression }\end{array}$ \\
\hline van Strien et al. (2010) & $584(295)$ & $\begin{array}{l}13.4(0.6) \\
15.2(0.5)\end{array}$ & No & 325018 & $\begin{array}{l}\text { Emotional, } \\
\text { eating (DEBQ) }\end{array}$ & $\begin{array}{l}\text { Depression } \\
\text { (Depressive } \\
\text { Mood List) }\end{array}$ & $\begin{array}{c}\text { Interaction b/w } \\
\text { s-allele and } \\
\text { depression on } \\
\text { DEBQ scores }\end{array}$ \\
\hline
\end{tabular}


Rozenblat et al., JOURNAL OF PSYCHiatric RESEARCH 84 (2017)

\begin{tabular}{|c|c|c|c|c|c|c|c|}
\hline \multirow[t]{2}{*}{ Author (year) } & $\begin{array}{l}\text { Total no. of } \\
\text { participants } \\
\text { (no. women) }\end{array}$ & $\begin{array}{c}\text { Mean age, } \\
\text { yrs (SD) }\end{array}$ & $\begin{array}{l}\text { Clinical } \\
\text { sample }\end{array}$ & $\begin{array}{c}\text { 5-HTTLPR } \\
\text { genotype } \\
\%\end{array}$ & $\begin{array}{l}\text { Outcome } \\
\text { (measures) }\end{array}$ & $\begin{array}{l}\text { Environmental } \\
\text { factor }\end{array}$ & Results \\
\hline & & & & LL LS SS & & & \\
\hline Karwautz et al. (2011) & $\begin{array}{c}256 \\
(128 \\
\text { discordant } \\
\text { sister-pairs })\end{array}$ & $25.6(8.4)$ & Half AN & 384318 & $\begin{array}{c}\text { AN } \\
\text { (EATATE-I } \\
\text { interview, } \\
\text { DSM-IV } \\
\text { diagnosis) }\end{array}$ & $\begin{array}{l}\text { Life events } \\
\text { (Oxford Risk } \\
\text { Factor } \\
\text { Inventory) }\end{array}$ & $\begin{array}{c}\text { Interaction } \\
\text { between s-allele } \\
\text { and life events, } \\
\text { specifically } \\
\text { problematic } \\
\text { parenting styles }\end{array}$ \\
\hline Akkermann et al. (2012) & $252(252)$ & $17.8(0.5)$ & No & $\begin{array}{l}103(1 / 1) \\
136(\mathrm{~s} /-)\end{array}$ & $\begin{array}{c}\text { Drive for } \\
\text { thinness, } \\
\text { Bulimia (EDI-2) }\end{array}$ & $\begin{array}{l}\text { Life events (self- } \\
\text { devised scale), } \\
\text { including } \\
\text { sexual, physical, } \\
\text { and emotional } \\
\text { abuse }\end{array}$ & $\begin{array}{c}\text { Interaction } \\
\text { between s-allele } \\
\text { and life events } \\
\text { on bulimia only } \\
\text { (interaction } \\
\text { with sexual } \\
\text { abuse for both } \\
\text { outcomes, none } \\
\text { for physical } \\
\text { abuse) }\end{array}$ \\
\hline Stoltenberg et al. (2012) & $439(284)$ & $22.5(6.2)$ & No & 334621 & $\begin{array}{c}\text { Disordered } \\
\text { eating (EAT-26) }\end{array}$ & $\begin{array}{c}\text { Life events } \\
\text { (Traumatic } \\
\text { Antecedent } \\
\text { Questionnaire) }\end{array}$ & $\begin{array}{c}\text { Interaction } \\
\text { between s-allele } \\
\text { and traumatic } \\
\text { events for } \\
\text { females only }\end{array}$ \\
\hline
\end{tabular}

Notes: $\mathrm{G} \times \mathrm{E}=$ gene $\times$ environment interaction; $\mathrm{AN}=$ anorexia nervosa; $\mathrm{BN}=$ bulimia nervosa; $\mathrm{CDI}=\mathrm{Children}$ 's Depression Inventory $($ Kovacs, 1985), CTI = Childhood Trauma Interview (Fink et al., 1995); DEBQ = Dutch Eating Behavior Questionnaire (van Strien, 2002); EAT-26= Eating Attitudes Test (Garner et al., 1982); EATATE-I = EATATE Lifetime Diagnostic Interview (Anderluh et al., 2009); EDE = Eating Disorders Examination (Fairburn and Cooper, 1993); EDI-2 = Eating Disorders Inventory-2 (Garner, 1991a); EDIC = Eating Disorders Inventory for Children and Adolescents (Garner, 1991b); MEBS = Minnesota Eating Behavior Survey (von Ranson et al., 2005). Results are significant at $p<0.05$ unless otherwise specified.

\section{Secondary data meta-analyses}

\subsection{Method}

\subsubsection{Inclusion criteria}

From the final 7 studies identified through systematic review, those that tested equivalent environmental or psychological variables were considered for a secondary data meta-analysis. Six suitable studies were identified (see Fig. 1). Data from one additional study (Richardson et al., 2008) were included in the secondary data analysis but not the systematic review, as it contained relevant variables (drawing from the same larger sample as Steiger et al., 2007) but did not explicitly analyze the $G \times$ E interaction with an ED-specific outcome in their publication. Authors were contacted with a request to provide data for reanalysis and an invitation to join the present study. All authors contributed their data via email attachment as an SPSS or Microsoft Excel file. Variables sought included participant ID, age, 
gender, BMI (if assessed), 5-HTTLPR genotype, and item-level data for the environmental and ED variables.

\subsubsection{Design}

Data from six studies (Akkermann et al., 2012; Karwautz et al., 2011; Racine et al., 2009; Richardson et al., 2008; Stoltenberg et al., 2012; Steiger et al., 2007; and van Strien et al., 2010) were combined to test four separate secondary data analyses: 5-HTTLPR $\times$ Traumatic Life Events to predict ED diagnosis or equivalent, 5-HTTLPR $\times$ Sexual and/or Physical Abuse to predict a BN-spectrum ED or equivalent, 5-HTTLPR $\times$ Depression to predict BNspectrum ED or equivalent, and 5-HTTLPR $\times$ Impulsiveness to predict ED diagnosis or equivalent.

\subsubsection{Data synthesis}

Full data sets from each study were provided. Overlapping participant data in Steiger et al. (2007) and Richardson et al. (2008) were removed by contributing authors prior to sending their data. Karwautz et al. (2011) was part of a European multicenter collaboration (The European Project), and data for the present study were drawn from the larger unpublished sample, including additional data from clinical BN patients. Data from The European Project were included only if they contained item-level responses to the Oxford Risk Factor Inventory (ORFI; Fairburn et al., 1998) to ensure consistent measurement of the environmental factor "traumatic life events" across studies. Item-level data were unavailable from some participating research centers and therefore the present sample size does not match that of Karwautz et al. (2011) but includes additional participants with a BN diagnosis.

Prior to combining datasets according to the below-mentioned procedures, missing data were imputed at the item-level where necessary using the median value (Tabachnick and Fidell, 2013), with missingness lower than 5\%. Participants with missing genetic data or summary scales (where item-level data were unavailable), were excluded from the analyses.

Measures of environmental and psychological factors used across studies were heterogeneous to varying extents. Most studies utilized different scales to assess ED status or examined different elements of disordered eating. Therefore, a complex process was necessary to integrate the variables to achieve compatibility for combined analysis, which is summarized below. Participant 5-HTTLPR genotypes across each study were coded as s-allele present (s/s and s/l genotypes) or s-allele absent (1/1 genotype), as the s-allele is argued to function in a genetically dominant manner (Lesch et al., 1996).

3.1.3.1. Analysis 1 - traumatic life events. Traumatic life events were determined according to 17 events (e.g., traumas/accidents, abuse, major health problems) that overlapped between scales used in Akkermann et al. (2012; self-devised scale), and Stoltenberg et al. (2012; Traumatic Antecedent Questionnaire, Herman \& van der Kolk, 1987). Fourteen of these events overlapped with The European Project (ORFI; Fairburn et al., 1998) data, which was scaled to match the 18-item (0-17 events) solution.

ED status or equivalent was determined by a total score above 5 and 3 on the Drive For Thinness and Bulimia Scales of the Eating Disorder Inventory-2 (EDI-2; Garner, 1991a), respectively, which are the recommended scale-level cut-offs for clinical-level disordered 
eating (Nevonen and Broberg, 2001; Norring and Sohlberg, 1988). In Stoltenberg et al. (2012), ED status or equivalent was determined by a total score of 20 or greater on the Eating Attitudes Test-26 (EAT-26; Garner et al., 1982), the established cut-off for likely clinicallevel eating pathology. A semistructured clinical interview, the EATATE (Anderluh et al., 2009), was used to identify ED diagnosis based on DSM-IV criteria (American Psychiatric Association [APA], 2000) in the European Project.

3.1.3.2. Analysis 2 - sexual and physical abuse. Sexual abuse and physical abuse were coded dichotomously in the European Project and Akkermann et al. (2012), and recoded into yes/no format in Richardson et al. (2008) and Steiger et al. (2007) if participants endorsed anything above "low" sexual or physical abuse, and in Stoltenberg et al. (2012) if abuse was "occasional" or greater. BN status or equivalent was established based on whether participant responses to items on the EDI-2 (Garner,1991a) in Akkermann et al. (2012) and on the EAT-26 (Garner et al., 1982) in Stoltenberg et al. (2012) endorsed DSM-IV (APA, 2000) BN-criteria, namely, engaging in regular binge eating, with loss of control, and engagement in compensatory behavior. In addition, participants whose scores on the EDI-2 Bulimia scale and EAT-26 Bulimia and Food Preoccupation scale were substantially elevated, suggesting likely clinical-range $\mathrm{BN}$, were classified in the $\mathrm{BN}$ group. $\mathrm{BN}$ was determined according to the EATATE (Anderluh et al., 2009) and DSM-IV criteria (APA, 2000) in the European Project, and by the Eating Disorders Examination (EDE; Fairburn and Cooper, 1993) in Steiger et al. (2007) and Richardson et al. (2008).

3.1.3.3. Analysis 3 - depression. Depression was coded dichotomously in the European Project using the ORFI (Fairburn et al., 1998) and in Richardson et al. (2008) as determined by the Structured Clinical Interview for DSM-IV Axis-I Disorders (SCID-I, First et al., 1996). Dimensional measurements were obtained in Akkermann et al. (2012) via the self-report version of the Montgomery-Åsberg Depression Rating Scale (MADRS-S; Montgomery and Åsberg, 1979), and van Strien et al. (2010) via the Depressive Mood List (Kandel and Davies, 1982). For compatibility with the European Project and Richardson et al. (2008), these were dichotomized. A cut-off score of 15 was selected for the MADRS-S according to research examining criterion validity (Svanborg and Åsberg, 2001; Svanborg and Ekselius, 2003). No cut-off score has been established for the Depressive Mood List. However, as there was complete overlap between these measures, participant scores on the Depressive Mood List were scaled to match MARDS-S responses and the same cut-off value was applied. BN status or equivalent was determined as in Analysis 2 for the European Project, Richardson et al. (2008), and Akkermann et al. (2012). BN status was based on participant responses to categorical questions investigating binge frequency, loss of control, and engagement in compensatory behaviors in van Strien et al. (2010).

3.1.3.4. Analysis 4 - impulsiveness. All studies assessed impulsiveness using the Barratt Impulsiveness Scale (BIS-11; Patton et al., 1995). ED status or equivalent was determined as in Analysis 1 for Akkermann et al. (2012) and Stoltenberg et al. (2012), while for Racine et al. (2009) this was determined by a mean score of 2.3 or greater on a self-report version 
of the EDE (EDE-Q; adopted from Fairburn and Cooper, 1993), as suggested by Mond et al. (2004).

\subsubsection{Statistical analyses}

Analyses were conducted using binary logistic regression to test main and interaction effects of 5-HTTLPR and the environmental or psychological factor in predicting ED/BN status. 5-HTTLPR was coded according to presence or absence of the low-function s-allele. In light of past findings suggesting the s-allele operates in a genetically dominant manner (e.g., Lesch et al., 1996), and in order to avoid issues relating to multiple testing, genotype grouping (s/s, s/l, $1 / 1)$ was not investigated. All analyses controlled for age by including the age, age $\times$ environment, and age $\times 5$-HTTLPR terms to the overall model. BMI was also controlled for where data were available. These interaction terms are necessary to adequately control for potential confounders, although they have been omitted from most $\mathrm{G} \times \mathrm{E}$ investigations in psychiatry to date (Keller, 2014). It was not possible to control for sex due to frequency distribution issues in the logistic regression. When examining sex differences by comparing a female only subsample to the overall sample in each analysis (a male-only subsample was not possible to due to frequency distribution), results were similar across all analyses, therefore only results for the larger, complete sample are displayed.

Finally, whereas the interaction term between gene and environmental or psychological factor is sufficient for testing a $\mathrm{G} \times \mathrm{E}$ interaction in logistic regression under a multiplicative model (as per past studies; e.g., Caspi et al., 2003; Karwautz et al., 2011; Steiger et al., 2012; also see Munafò et al., 2009), three additional statistics were computed to quantify the interaction from an additive perspective: the relative excess risk due to interaction (RERI), the attributable portion due to the interaction (AP), and the synergy index (S). When an interaction is present in the data, RERI and AP will be greater than 0 , whereas $\mathrm{S}$ will be greater than 1 . These additive models were conducted using Stata version 13. Estimates of these interaction effects were derived from relative risk ratios rather than odds ratios, as: (1) the formulae for RERI, AP, and S were designed to use with RR values, and (2) substituting OR values for RR values in these formula will over-estimate the interaction effects in cases where the baseline prevalence is not rare (e.g., greater than $10 \%$ prevalence; VanderWeele and Knol, 2014). To facilitate calculation of RR values, the two continuous predictors-traumatic experiences and impulsivity-were converted into categorical forms. Trauma history was split into no instances reported versus $1+$ instances reported. As the appropriate cut-point for the impulsivity measure is unclear, several percentiles were trialed (5th, 10th, 15th, 20th, and 25th). Substantive conclusions did not change depending on the cut-off applied, and as such, results are reported for the lowest cut-off (5th percentile) to conceptually reflect those with lowest reported levels of impulsivity.

\subsection{Results}

\subsubsection{Analysis 1: traumatic life events}

The sample comprised 909 individuals (65.7\% female), from the following studies: two community samples, Stoltenberg et al. (2012; $N=436,65.1 \%$ female), Akkermann et al. 
(2012; $N=369,56.6 \%$ female), and a discordant sister-pair sample, the European Project $(N=104,100 \%$ female $)$.

Overall, 169 (18.6\%) participants met criteria for an ED or equivalent. 5-HTTLPR frequencies $(1 / 1=333,1 / \mathrm{s}=415, \mathrm{~s} / \mathrm{s}=161)$ met the Hardy-Weinberg equilibrium, $\chi^{2}=2.55, d f=1$, $p>0.05$. Traumatic Life Events were scored 0 to $17,(M=2.38$ events, $S D=2.54)$, and were positively skewed. Results of the logistic regression are displayed in Table 3.

As evident in Table 3, while there was no effect of traumatic events or genotype alone, presence of the s-allele was related to significantly greater likelihood of an ED for those who had experienced more traumatic life events compared to those with the $1 / 1$ genotype $(O R=1.23$, see Fig. 2). A small but significant main effect of age was also noted. From an additive perspective, however, none of the interaction indices reported significant findings to support an interaction effect: RERI $=-0.90(95 \%$ CIs: $-4.17,2.36), p=0.587 ; \mathrm{AP}=-0.53$ (95\% CIs: $-2.85,1.79), p=0.654$; and $\mathrm{S}=0.44$ (95\% CIs: 0.01, 16.53), $p=0.657$.

Table 3. Main and Interaction Effects of 5-HTTLPR s-allele and each environmental factor, controlling for age (and BMI where possible) by including all covariate $\times$ gene and covariate $\times$ environment interaction terms, in predicting ED Status (Analyses 1 and 4) and BN status (Analyses 2 and 3)

\begin{tabular}{|c|c|c|c|c|c|}
\hline & \multirow[b]{2}{*}{ B } & \multirow[b]{2}{*}{ Odds ratio } & \multicolumn{2}{|c|}{$95 \% \mathrm{CI}$ for odds ratio } & \multirow[b]{2}{*}{ Sig. } \\
\hline & & & Lower & Upper & \\
\hline \multicolumn{6}{|c|}{ Analysis 1: Traumatic life events $(N=909)$} \\
\hline Constant & -4.02 & & & & \\
\hline 5-HTTLPR & 1.01 & 2.75 & 0.78 & 9.70 & 0.115 \\
\hline Traumatic Events & 0.01 & 0.91 & 0.82 & 1.25 & 0.906 \\
\hline 5 -HTTLPR $\times$ Traumatic Events & 0.21 & 1.23 & 1.06 & 1.44 & 0.006 \\
\hline Age & 0.12 & 1.12 & 1.07 & 1.18 & $<0.001$ \\
\hline Age $\times 5-$ HTTLPR & -0.06 & 0.94 & 0.89 & 0.99 & 0.029 \\
\hline Age $\times$ Traumatic Events & -0.002 & 1.00 & 0.99 & 1.00 & 0.432 \\
\hline \multicolumn{6}{|c|}{ Analysis 2: Sexual/Physical abuse $(N=1097)$} \\
\hline \multicolumn{6}{|l|}{ Sexual abuse } \\
\hline Constant & -4.77 & & & & \\
\hline 5-HTTLPR & 0.49 & 1.64 & 0.50 & 5.32 & 0.413 \\
\hline Sexual Abuse & 2.15 & 8.56 & 2.16 & 33.92 & 0.002 \\
\hline 5-HTTLPR $\times$ Sexual Abuse & 0.53 & 1.69 & 0.74 & 3.89 & 0.214 \\
\hline Age & 0.14 & 1.15 & 1.10 & 1.19 & $<0.001$ \\
\hline Age $\times 5-$ HTTLPR & -0.02 & 0.98 & 0.94 & 1.03 & 0.516 \\
\hline Age $\times$ Sexual Abuse & -0.06 & 0.94 & 0.90 & 0.99 & 0.013 \\
\hline \multicolumn{6}{|l|}{ Physical abuse } \\
\hline Constant & -4.98 & & & & \\
\hline 5-HTTLPR & 0.45 & 1.57 & 0.47 & 5.22 & 0.461 \\
\hline Physical Abuse & 1.57 & 4.79 & 1.37 & 16.70 & 0.014 \\
\hline 5-HTTLPR $\times$ Physical Abuse & 0.53 & 1.70 & 0.85 & 3.41 & 0.135 \\
\hline Age & 0.14 & 1.15 & 1.10 & 1.21 & $<0.001$ \\
\hline Age $\times 5-$ HTTLPR & -0.02 & 0.99 & 0.94 & 1.03 & 0.536 \\
\hline Age $\times$ Physical Abuse & -0.05 & 0.95 & 0.91 & 0.99 & 0.045 \\
\hline
\end{tabular}


Rozenblat et al., Journal of PSychiatric Research 84 (2017)

\begin{tabular}{|c|c|c|c|c|c|}
\hline \multicolumn{6}{|l|}{ Table 3. Continued } \\
\hline & $\mathrm{B}$ & Odds ratio & Lower & Upper & Sig. \\
\hline \multicolumn{6}{|l|}{ Sexual and Physical abuse } \\
\hline Constant & -4.77 & & & & \\
\hline 5-HTTLPR & 0.63 & 1.88 & 0.59 & 6.04 & 0.288 \\
\hline Sexual and Physical Abuse & 2.45 & 11.53 & 2.26 & 58.68 & 0.003 \\
\hline 5-HTTLPR $\times$ Sexual and Physical Abuse & 1.15 & 3.15 & 1.09 & 9.09 & 0.034 \\
\hline Age & 0.14 & 1.15 & 1.10 & 1.19 & $<0.001$ \\
\hline Age $\times 5-$ HTTLPR & -0.02 & 0.98 & 0.93 & 1.03 & 0.381 \\
\hline Age $\times$ Sexual and Physical Abuse & -0.08 & 0.92 & 0.87 & 0.97 & 0.003 \\
\hline \multicolumn{6}{|l|}{ Analysis 3: Depression $(N=1,254)$} \\
\hline Constant & -7.39 & & & & \\
\hline 5-HTTLPR & -0.25 & 0.78 & 0.07 & 8.52 & 0.780 \\
\hline Depression & 0.13 & 1.14 & 0.05 & 24.77 & 0.934 \\
\hline 5-HTTLPR $\times$ Depression & 0.88 & 2.41 & 0.74 & 7.88 & 0.146 \\
\hline Age & 0.26 & 1.30 & 1.10 & 1.54 & 0.003 \\
\hline BMI & 0.03 & 1.03 & 0.85 & 1.24 & 0.770 \\
\hline Age $\times$ BMI & -0.001 & 1.00 & 0.99 & 1.01 & 0.821 \\
\hline Age $\times 5$-HTTLPR & 0.04 & 1.04 & 0.96 & 1.11 & 0.338 \\
\hline Age $\times$ Depression & -0.10 & 0.91 & 0.84 & 0.98 & 0.011 \\
\hline $\mathrm{BMI} \times 5-\mathrm{HTTLPR}$ & -0.02 & 0.98 & 0.90 & 1.08 & 0.724 \\
\hline BMI $\times$ Depression & 0.07 & 1.08 & 0.96 & 1.21 & 0.205 \\
\hline \multicolumn{6}{|l|}{ Analysis 4: Impulsivity $(N=1,114)$} \\
\hline Constant & -2.59 & & & & \\
\hline 5-HTTLPR & 0.46 & 1.59 & 0.14 & 18.06 & 0.710 \\
\hline Impulsiveness & 0.001 & 1.00 & 0.95 & 1.06 & 0.971 \\
\hline 5-HTTLPR $\times$ Impulsiveness & 0.01 & 1.01 & 0.98 & 1.05 & 0.500 \\
\hline Age & 0.03 & 1.03 & 0.88 & 1.19 & 0.733 \\
\hline Age $\times 5-$ HTTLPR & -0.04 & 0.96 & 0.90 & 1.03 & 0.245 \\
\hline Age $\times$ Impulsiveness & $<0.01$ & 1.00 & 1.00 & 1.00 & 0.816 \\
\hline
\end{tabular}

Odds ratio $=\operatorname{Exp}(B)$ 

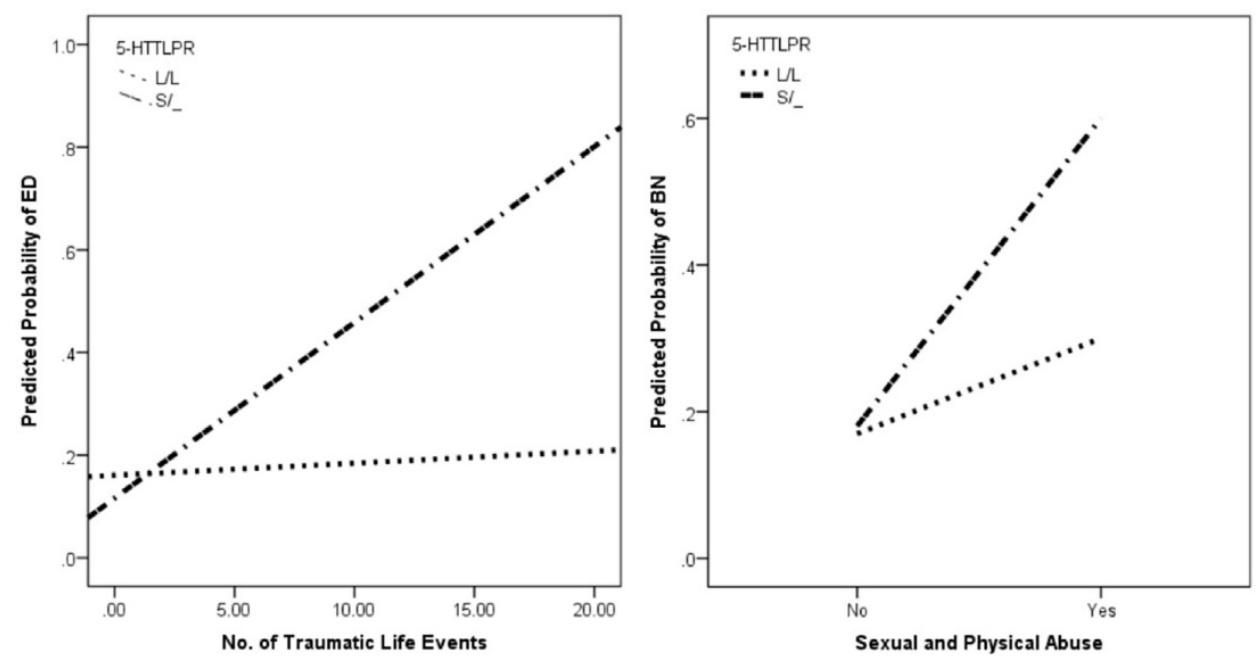

Figure 2. Significant $G \times E$ interactions between 5-HTTLPR and environmental factors: (1) Traumatic life events and (2) Sexual and physical abuse.

\subsubsection{Analysis 2: sexual and/or physical abuse}

The sample comprised 1,097 individuals ( $71.8 \%$ female), from the following studies: two community samples, Stoltenberg et al. (2012; $N=436,65.1 \%$ female), Akkermann et al. (2012; $N=369,56.6 \%$ female), one clinical sample from Steiger et al. (2007) and Richardson et al. (2008), ( $N=127,100 \%$ female) and a discordant sister-pair sample, the European Project $(N=168,63 \%$ controls, $100 \%$ female $)$.

Overall, 221 (20.1\%) participants met criteria for BN or equivalent. Three-hundred and fourteen $(28.5 \%)$ participants reported experiencing physical abuse, $165(15 \%)$ reported sexual abuse, and $85(7.7 \%)$ reported both physical and sexual abuse. 5-HTTLPR frequencies $(1 / 1=407,1 / s=492, s / s=201)$ deviated from the Hardy-Weinberg equilibrium, $\chi^{2}=5.85$, $d f=1, p=0.02$.

Results outlined in Table 3 show significant main effects for sexual abuse $(O R=8.56)$, physical abuse $(O R=4.79)$, and both sexual and physical abuse combined ( $O R=11.53)$. There was a significant $\mathrm{G} \times \mathrm{E}$ interaction $(O R=3.15)$, whereby participants with the s-allele who experienced both sexual and physical abuse were more likely to endorse BN status compared to those with the $1 / 1$ genotype (Fig. 2). There was a main effect of age, and increased likelihood of $\mathrm{BN}$ was also significantly predicted by an interaction between (younger) age and each of the abuse variables.

From an additive perspective, a number of the interaction indices displayed significant findings to also support an interaction effect for physical abuse: RERI $=1.32$ (95\% CIs: 0.06, 2.58), $p=0.040$; AP $1 / 40.40$ (95\% CIs: 0.09, 0.72), $p=0.012$; but not $S=2.40$ (95\% CIs: 0.81, 7.13), $p=0.116$, and to support an interaction for sexual abuse RERI $=2.26$ (95\% CIs: 0.05 , 4.47), $p=0.045 ; \mathrm{AP}=0.49$ (95\% CIs: 0.13, 0.85), $p=0.007$; but not $\mathrm{S}=2.70$ (95\% CIs: 0.82 , $8.90), p=0.102$. All indices supported an interaction on additive scale for both sexual and physical abuse $\times 5$-HTTLPR, RERI $=5.16$ (95\% CIs: 0.73, 9.60), $p=0.022 ; \mathrm{AP}=0.70$ (95\% CIs: $0.43,0.98), p<0.001 ; \mathrm{S}=5.41$ (95\% CIs: 1.10, 26.71), $p=0.038$. 


\subsubsection{Analysis 3: depression}

The sample comprised 1,254 individuals (62.5\% female), from the following studies: two community samples, Akkermann et al. (2012; $N=369,56.6 \%$ female) and van Strien et al. (2010; $N=623,51.2 \%$ female), one clinical sample, Richardson et al. $(2008 ; N=89,100 \%$ female) and a discordant sister-pair sample, the European Project $(N=168,63 \%$ controls, $100 \%$ female).

Overall, 172 (13.7\%) participants met criteria for BN or equivalent, while $184(14.7 \%)$ participants met criteria for depressed mood. 5-HTTLPR frequencies $(1 / 1=438,1 / \mathrm{s}=612$, s/s $=205$ ) met the Hardy-Weinberg equilibrium, $\chi^{2}=0.14, d f=1, p>0.05$. Results of the logistic regression revealed no main or interaction effects of depression and 5-HTTLPR in predicting BN status (Table 3). Similar to the pattern observed in Analysis 2, younger age interacted with depressive status to predict greater likelihood of BN. There was also no support for an interaction effect under an additive model, RERI $=0.15$ (95\% CIs: $-0.95,1.26), p=$ 0.785 and $\mathrm{AP}=0.13$ (95\% CIs: $-0.77,1.03), p=0.778$. S could not be reliably computed for this interaction.

\subsubsection{Analysis 4: impulsiveness}

The sample comprised 1,122 individuals (72.2\% female) from three community samples, Stoltenberg et al. (2012; $N=436,65.1 \%$ female), Akkermann et al. (2012; $N=369,56.6 \%$ female), and Racine et al. (2009; $N=317,100 \%$ female).

Overall, 224 (20.0\%) participants met ED criteria or equivalent. 5-HTTLPR frequencies $(1 / 1=384,1 / s=545, \mathrm{~s} / \mathrm{s}=193)$ met the Hardy-Weinberg equilibrium, $\chi^{2}<0.01, d f=1, p>0.05$. Impulsivity was measured using the Barratt Impulsiveness Scale Version 11 (BIS-11; Patton et al., 1995), and was normally distributed. Data did not meet the assumption of linearity between continuous independent variables and the logit $(p=0.003)$, suggesting that results may present an underestimation of the relationship (Hosmer and Lemeshow, 1989). Results of the logistic regression revealed no main or interaction effects of impulsiveness and 5-HTTLPR in predicting ED status (Table 3), which was supported by the indices measuring additive interaction, RERI $=-1.18$ (95\% CIs: $-4.22,1.86), p=0.448$; $\mathrm{AP}=-0.85$ (95\% CIs: $-2.49,0.78), p=0.307$; and S = 0.24 (95\% CIs: 0.03, 1.83), $p=0.170$.

\section{Discussion}

To our knowledge, this is the first systematic review and secondary data meta-analysis investigating the role of 5-HTTLPR $\times$ environment and psychological factor interactions in risk for eating pathology. The aim was to summarize and reanalyze existing $\mathrm{G} \times \mathrm{E}$ research on eating disorder-related outcomes investigating the 5-HTTLPR polymorphism, in the largest sample tested to date, in order to elucidate the current state of knowledge and provide guidance for future $\mathrm{G} \times \mathrm{E}$ studies in the field. Results of the secondary data metaanalysis revealed that when testing deviations from an additive model of interaction, the experience of sexual abuse, physical abuse, and both sexual and physical abuse each interacted with the s-allele of 5-HTTLPR to predict increased risk of bulimia-spectrum eating pathology. The significant interaction between 5-HTTLPR and both sexual and physical abuse (but not only one) was also supported from a multiplicative perspective, although 
there was no support for sexual abuse or physical abuse considered alone. In addition, there was a significant interaction between traumatic life events and 5-HTTLPR to predict an increased risk of eating pathology under the multiplicative model only. No effects were noted for the potential risk factors of depression and impulsiveness under either model.

Other noteworthy results include the large direct effects of sexual abuse and physical abuse on $\mathrm{BN}$-spectrum disorders, an association demonstrated in previous meta-analyses (Chen et al., 2010; Norman et al., 2012; Smolak and Murnen, 2002). Conversely, there were no main effects of 5-HTTLPR genotype in any analyses, contrary to some past findings (Calati et al., 2011; Lee and Lin, 2010), although aligned with others (Castellini et al., 2012; Solmi et al., 2016).

The current $\mathrm{G} \times \mathrm{E}$ findings suggest that individuals with the "risky" genotype may be relatively resilient to low levels of environmental risk but disproportionately affected by greater environmental adversity (e.g., experiencing numerous types of abuse). From a biological perspective, it is plausible that this may function via the lowered serotonin transcription associated with the s-allele of 5-HTTLPR, leading to reduced availability of a key neurotransmitter in the stress response system (van Eekelen et al., 2012).

The present results demonstrate some links to findings in the depression field, where greater traumatic life events, including childhood abuse, have been found to interact with 5-HTTLPR to predict depression (Karg et al., 2011; Nugent et al., 2011), although the interaction between life events and 5-HTTLPR is not undisputed (Munafò et al., 2009; Risch et al., 2009). One caveat is that "traumatic life events" is a heterogonous concept. The types of events measured, scaling process, timing of events, age of participants, etc., may vary greatly, perhaps accounting for some inconsistency in $\mathrm{G} \times \mathrm{E}$ findings in the depression field (Uher and McGuffin, 2008). Careful consideration of these factors is encouraged for future analyses.

Aside from consistent measurement of environmental variables, another key issue affecting $G \times E$ research is low statistical power. Use of small sample sizes with insufficient power to detect $G \times E$ interactions has been a major point of criticism in $G \times E$ research for increasing risk of both false negative and false positive findings (Button et al., 2013). Sample sizes necessary to detect $G \times E$ effects are far bigger than typically involved in psychology (Luan et al., 2001), with one calculation of minimum sample size necessary to detect a large $\mathrm{G} \times$ E interaction effect at $80 \%$ power, assuming no measurement error, $N=600$ (Duncan and Keller, 2011). This increases substantially if only moderate effect sizes are involved. The median sample size of studies identified by the systematic review was 288 , which is considered substantial in the ED field but lacking for genetic analyses. This is a particularly challenging limitation in light of the difficulty of obtaining genetic samples and highlights the immense value of the present collaboration, which has allowed us to utilize existing resources to maximize sample size and further knowledge regarding $G \times E$ effects in eating pathology.

One factor that may yet affect accuracy of the present findings is the possibility of publication bias amongst the studies identified by the systematic review. This has been noted in past $G \times E$ research, with one review reporting that significant findings were observed in $96 \%$ of initial $\mathrm{G} \times \mathrm{E}$ investigations but in only $27 \%$ of subsequent replication attempts (Duncan and Keller, 2011; Duncan et al., 2014). However, others argue that many instances 
of nonreplication are related to methodological issues, including inadequate measurement of traumatic life events (Caspi et al., 2010; Monroe and Reid, 2008). In any case, the tendency for positive findings to be more readily published, and null findings perhaps less likely to be initially submitted, can have a large effect on the accuracy of published studies by inflating false positive results (Dick et al., 2015; Ioannidis et al., 2014). It is therefore vital, for the success of future collaborative meta-analyses, for researchers to publish both significant and nonsignificant findings and for journals to support this initiative, while emphasizing the use of reliable environmental measures.

Aside from the benefits of large sample sizes and resource efficiency in the present investigation, it further improved upon existing $G \times E$ research in eating pathology by correctly controlling for the potential effect of confounding variables (Keller, 2014). The inclusion of all necessary interaction terms was also facilitated by the large sample sizes investigated and should be aimed for in future studies. Another strength of the present study was that it examined $\mathrm{G} \times \mathrm{E}$ interactions under both additive and multiplicative models of interaction. Most previous studies using a logistic regression model to assess their data have tested deviations from a multiplicative model. Conversely, studies of community samples with continuous outcome variables typically use linear regression models, which test deviations from an additive model. As the two methods produce somewhat different results, with the latter generally more conservative, caution should be taken in comparing the results of these models, and indeed, this may account for some of the discrepant findings in $\mathrm{G} \times \mathrm{E}$ research.

The present secondary data meta-analysis is not without limitations, primarily due to the need to harmonize heterogeneous datasets, which tested both community and clinical samples and contained varied measures of environmental and psychological factors and eating symptoms. The investigation of the 5-HTTLPR $\times$ depression interaction was in particular hindered by variability in the measurement of depression between studies. These methodological issues may explain why this interaction was not found to be significant in the present analysis, contrary to findings in two of the initial studies (Mata and Gotlib, 2011; van Strien et al., 2010).

Nonetheless, the present study provides a detailed overview of current $\mathrm{G} \times \mathrm{E}$ findings involving 5-HTTLPR in the ED field, including studies assessing psychological variables. Subsequent research should focus on continued replication with large sample sizes, possibly best achieved through ongoing collaboration between researchers, given the resourceintensive nature of genetic research and scarcity of clinical ED samples. Such investigations would be best facilitated by researchers adopting standardized, or easily comparable, measures of environmental and psychological factors and eating symptoms that have excellent psychometric properties. Selection of measures should be carefully deliberated, both to maximize construct validity and to reduce measurement error, which can substantially increase statistical power (Bakermans-Kranenburg and van Ljzendorn, 2014). Polymorphisms and environmental or psychological factors selected should also be carefully justified, particularly in light of sample size restrictions (Dick et al., 2015).

Future studies may also benefit from adopting a differential susceptibility approach to $\mathrm{G} \times \mathrm{E}$ investigations. This hypothesis posits that certain alleles may be better conceptualized as conferring "plasticity" in response to environmental stimuli, with alleles linked to 
poorer outcomes under negative environments conversely linked to better outcomes in positive environments (Belsky and Pluess, 2009). Such an analysis was not possible in the current paper due to lack of data assessing positive environments, however this pattern has been demonstrated for various polymorphisms, including 5-HTTLPR, in non-ED literature (see Bakermans-Kranenburg and van Ljzendorn, 2011; for a metaanalysis; Hankin et al., 2011). Accordingly, studies should include environmental measures that range from positive to negative in nature, such as parenting, peer relationships, or positive life events.

In sum, the present collaboration constitutes a large step forward in increasing knowledge of how genetics may moderate the manner in which environmental and psychological influences affect the likelihood of ED development. Given the ongoing uncertainty regarding why thus far identified risk factors appear to contribute toward ED development for some individuals but not others, genetics may be an important missing puzzle piece in identifying the source of individual variation in susceptibility to eating pathology.

Role of funding source - Financial support was received from the European Union (Framework-V Multicenter Research Grant, QK1-1999-916), the University of Melbourne Early Career Researcher Grants Scheme (2014, 1350035), U.S. National Institute of Mental Health (1R15MH077654-01A1), the Estonian Ministry of Education and Science (IUT20-40 and IUT 42-2), the National Institute of Health and Michigan State University (T32-MH070343 and \#05-IRGP-883), the Quebec government's Joint CQRS-FRSQ-MSSS Program in Mental Health (SR-4306), the Canadian Institute of Health Research (MOP-57929), the Dutch Organization for Scientific Research (no. 400-05-051), and the Radboud University Nijmegen. None of these institutions had any role in the study design, collection, analysis, and interpretation of data, preparation of the manuscript, or decision to submit the manuscript for publication.

Contributors - Ms. Rozenblat was responsible for conducting all analyses and preparing all sections of the manuscript. Ms. Ong contributed to the systematic review section, including searching, recording results, evaluating the studies, and contributing to that section of the manuscript. Drs. Krug and Fuller-Tyszkiewicz contributed to study design and editing drafts of the manuscript, and Dr. Fuller-Tyszkiewicz also contributed to the analyses section. Remaining authors were involved in the collection of data. All authors contributed to and approved the final manuscript.

Conflict of interest - None declared.

Acknowledgments - This paper forms part of Vanja Rozenblat's PhD with publication undertaken at the University of Melbourne.

\section{References}

Akkermann, K., Kaasik, K., Kiive, E., Nordquist, N., Oreland, L., Harro, J., 2012. The impact of adverse life events and the serotonin transporter gene promotor polymorphism on the development of eating disorder symptoms. J. Psychiatric Res. 46, 38e43.

Akkermann, K., Hiio, K., Villa, I., Harro, J., 2011. Food restriction leads to binge eating dependent upon the effect of brain-derived neurotrophic factor Val66Met polymorphism. Psychiatry Res. $185,39 \mathrm{e} 43$.

Aliev, F., Latendresse, S.J., Bacanu, S.A., Neale, M.C., Dick, D.M., 2014. Testing for measured geneenvironment interaction: problems with the use of cross-product terms and a regression model reparameterization solution. Behav. Genet. 44 (2), $165 \mathrm{e} 181$. 
Anderluh, M., Tchanturia, K., Rabe-Hesketh, S., Collier, D., Treasure, J., 2009. Lifetime course of eating disorders: design and validity testing of a new strategy to define the eating disorders phenotype. Psychol. Med. 39, 105e114.

American Psychiatric Association, 2000. Diagnostic and Statistical Manual of Mental Disorders, fourth ed. Author, Washington, DC. text rev.

Bakermans-Kranenburg, M.J., van Ljzendorn, M.H., 2011. Differential susceptibility to rearing environment depending on dopamine-related genes: new evidence and a meta-analysis. Dev. Psychopathol. 23, 39e52.

Bakermans-Kranenburg, M.J., van Ljzendorn, M.H., 2014. The hidden efficacy of interventions: gene $\times$ environment experiments from a differential susceptibility perspective. Annu. Rev. Psychol. 66, 381e409.

Belsky, J., Pluess, M., 2009. Beyond diathesis stress: differential susceptibility to environmental influences. Psychol. Bull. 135 (6), 885e908.

Bulik, C., Thornton, L.M., Root, T.L., Pisetky, E.M., Lichtenstein, P., Pederson, N.L., 2010. Understanding the relation between anorexia nervosa and bulimia nervosa in a Swedish national twin sample. Biol. Psychiatry 67, 71e77.

Bulik, C., Sullivan, P., Tozzi, F., Furberg, H., Lichtenstein, P., Pedersen, N., 2006. Prevalence, heritability and prospective risk factors for anorexia nervosa. Arch. Gen. Psychiatry 63, 305e312.

Button, K.S., Ioannidis, J.P.A., Mokrysz, C., Nosek, B.A., Flint, J., Robinson, E.S.J., Munafò, M.R., 2013. Power failure: why small sample size undermines the reliability of neuroscience. Nat. Rev. Neurosci. 14, 365e376.

Calati, R., De Ronchi, D., Bellini, M., Serretti, A., 2011. The 5-HTTLPR polymorphism and eating disorders: a meta-analysis. Int. J. Eat. Disord. 44, 191e199.

Caspi, A., Hariri, A.R., Holmes, A., Uher, R., Moffitt, T.E., 2010. Genetic sensitivity to the environment: the case of the serotonin transporter gene and its implications for studying complex disease and traits. Am. J. Psychiatry 167 (5), 509e527.

Caspi, A., Sugden, K., Moffitt, T.E., Taylor, A., Craig, I.W., Harrington, H., McClay, J., Mill, J., Martin, J., Braithwaite, A., Poulton, R., 2003. Influence of life stress on depression: moderation by a polymorphism in the 5-HTT gene. Science 301, 386e389.

Castellini, G., Ricca, V., Lelli, L., Bagnoli, S., Lucenteforte, E., Faravelli, C., Sorbi, S., Nacmias, B., 2012. Association between serotonin transporter gene polymorphism and eating disorders outcome: a 6-year follow up study. Am. J. Med. Genet. B 159, 491e500.

Chen, L.P., Murad, M.H., Paras, M.L., Colbenson, K.M., Sattler, A.L., Goranson, E.N., Elamin, M.B., Seime, R.J., Shinozaki, G., Prokop, L.J., Zirakzadeh, A., 2010. Sexual abuse and lifetime diagnosis of psychiatric disorders: systematic review and meta-analysis. Mayo Clin. Proc. 85 (7), $618 \mathrm{e} 629$.

Culbert, K.M., Racine, S.E., Klump, K.L., 2015. Research review: what we have learned about the causes of eating disorders - a synthesis of sociocultural, psychological, and biological research. J. Child Psychol. Psychiatry 56 (11), 1141e1164.

Culverhouse, R.C., Bowes, L., Breslau, N., Nurnberger Jr., J.I., Burmeister, M., Fergusson, D.M., Munafò, M., Saccone, N.L., Bierut, L.J., 2013. Protocol for a collaborative meta-analysis of 5HTTLPR, stress, and depression. BMC Psychiatry 13, 340.

Dick, D.M., Agrawal, A., Keller, M.C., Adkins, A., Aliev, F., Monroe, S., Hewitt, J.K., Kendler, K.S., Sher, K.J., 2015. Candidate gene - environment interaction research: reflections and recommendations. Perspect. Psychol. Sci. 10 (1), 37e59. 
Downs, S.H., Black, N., 1998. The feasibility of creating a checklist for the assessment of the methodological quality both of randomised and non-randomised studies of health care interventions. J. Epidemiol. Commun. Health 52, 377e384.

Duncan, L.E., Keller, M.C., 2011. A critical review of the first 10 years of candidate gene-by-environment interaction research in psychiatry. Am. J. Psychiatry 168, 1041e1049.

Duncan, L.E., Pollastri, A.R., Smoller, J.W., 2014. Mind the gap: why many geneticists and psychological scientists have discrepant views about gene-environment interaction $(\mathrm{G} \times \mathrm{E})$ research. Am. Psychol. 69 (3), 249e268.

Fairburn, C.G., Cooper, P., 1993. The eating disorders examination. In: Fairburn, C., Wilson, G. (Eds.), Binge Eating: Nature, Assessment, and Treatment, twelfth ed. Guilford, New York, pp. 317e360.

Fairburn, C.G., Doll, H.A., Welch, S.L., Hay, P.J., Davies, B.A., O’Connor, M.E., 1998. Risk factors for binge eating disorder: a community-based, case-control study. Arch. Gen. Psychiatry 55 (5), 425e432.

Fairweather-Schmidt, A.K., Wade, T.D., 2015. Changes in genetic and environmental influences on disordered eating between early and late adolescence: a longitudinal twin study. Psychol. Med. 45 (15).

Fink, L.A., Bernstein, D., Handelsman, L., Foote, J., Lovejoy, M., 1995. Initial reliability and validity of the childhood trauma interview: a new multi-dimensional measure of childhood interpersonal trauma. Am. J. Psychiatry 152 (9), 1329e1335.

First, M.B., Spitzer, R.L., Gibbon, M., Williams, J.B.W., 1996. Structured Clinical Interview for DSMIV Axis I Disorders - Patient Edition (SCID-I/P, Version 2.0). Biometrics Research, New York State Psychiatric Institute, New York, NY.

Garner, D.M., 1991a. Eating Disorders Inventory-2 Professional Manual. Psychological Assessment Resources, Inc., Odessa, FL.

Garner, D.M., 1991b. Eating Disorders Inventory-C. Psychological Assessment Resources, Lutz, FL.

Garner, D.M., Olmsted, M.P., Bohr, Y., Garfinklel, P.E., 1982. The eating attitudes test: psychometric features and clinical correlates. Psychol. Med. 12, 871e878.

Hankin, B.L., Nederhof, E., Oppenheimer, C.W., Jenness, J., Young, J.F., Abela, J.R.Z., Smolen, A., Ormel, J., Oldenhinkel, A.J., 2011. Differential susceptibility in youth: evidence that 5-HTTLPR $\times$ positive parenting is associated with positive affect "for better and worse." Transl. Psychiatry 1, e44.

Heils, A., Teufel, A., Petri, S., Stöber, G., Riederer, P., Bengel, D., Lesch, K.P., 1996. Allelic variation of human serotonin transporter gene expression. J. Neurochem. 66, 2621e2624.

Herman, J.L., van der Kolk, B., 1987. Traumatic antecedents of border-line personality disorder. In: van der Kolk, B. (Ed.), Psychological Trauma. American Psychiatry Press, Washington, DC, pp. $111 \mathrm{e} 126$.

Hosmer, D.W., Lemeshow, S., 1989. Applied Logistic Regression. Wiley, New York.

Ioannidis, J.P.A., Munafò, M.R., Fusar-Poli, P., Nosek, B.A., David, S.P., 2014. Publication and other reporting biases in cognitive sciences: detection, prevalence, and prevention. Trends Cogn. Sci. 18 (5), $235 \mathrm{e} 241$.

Kandel, D.B., Davies, M., 1982. Epidemiology of depressive mood in adolescents: an empirical study. Archives General Psychiatry 939, 1205e1212.

Karg, K., Burmeister, M., Sheddan, K., Sen, S., 2011. The serotonin transporter promotor variant (5-HTTLPR), stress, and depression meta-analysis revisited: evidence of genetic moderation. Archives General Psychiatry 68 (5), 444e454. 
Karwautz, A.F.K., Wagner, G., Waldherr, K., Nader, I.W., Fernandez-Aranda, F., Estivill, X., Holliday, J., Collier, D.A., Treasure, J.L., 2011. Gene-environment interaction in anorexia nervosa: relevance of non-shared environment and the serotonin transporter gene. Mol. Psychiatry 16, $590 \mathrm{e} 592$.

Keller, M.C., 2014. Gene × environment interaction studies have not properly controlled for potential confounders: the problem and the (simple) solution. Biol. Psychiatry 75, $18 \mathrm{e} 24$.

Kovacs, M., 1985. The children's depression inventory (CDI). Psychopharmacol. Bull. 21, 995e1124.

Lee, Y., Lin, P.Y., 2010. Association between serotonin transporter gene polymorphism and eating disorders: a meta-analytic study. Int. J. Eat. Disord. 43, 498e504.

Lesch, K.P., Bengel, D., Heils, A., Sabol, S.Z., Greenberg, B.D., Petri, S., Benjamin, J., Müller, C.R., Hamer, D.H., Murphy, D.L., 1996. Association of anxiety-related traits with a polymorphism in the serotonin transporter gene regulatory region. Science 274 (5295), 1527e1531.

Lu, Y.A., Lee, S.Y., Chen, S.L., Chen, S.H., Chu, C.H., Tzeng, N.S., Lee, I.H., 2011. Gene-temperament interactions might distinguish between bipolar I and bipolar II disorders: a cross-sectional survey of Han Chinese in Taiwan. J. Clin. Psychiatry 73 (3), 1e478.

Luan, J.A., Wong, M.Y., Day, N.E., Wareham, N.J., 2001. Sample size determination for studies of gene-environment interaction. Int. J. Epidemiol. 30, 1035e1040.

Mandelli, L., Mazza, M., Martinotti, G., Di Nicola, M., Tavian, D., Colombo, E., Missaglia, S., De Ronchi, D., Colombo, R., Janiri, L., Serretti, A., 2009. Harm avoidance moderates the influence of serotonin transporter gene variants on treatment outcome in bipolar patients. J. Affect. Disord. 119 (1), 205e209.

Mata, J., Gotlib, I.H., 2011. 5-HTTLPR moderates the relationship between changes in depressive and bulimic symptoms in adolescent girls: a longitudinal study. Int. J. Eat. Disord. 44, 383e388.

Moher, D., Liberati, A., Tetzlaff, J., Altman, D.G., the PRISMA Group, 2010. Preferred reporting items for systematic reviews and meta-analyses: the PRISMA statement. Int. J. Surg. 8, 336e341.

Mond, J.M., Hay, P.J., Rodgers, B., Owen, C., Beumont, P.J.V., 2004. Validity of the Eating Disorders Examination Questionnaire (EDE-Q) in screening for eating disorders in community samples. Behav. Res. Ther. 42, 551e567.

Monroe, S.M., Simons, A.D., 1991. Diathesis-stress theories in the context of life stress research: implications for the depressive disorders. Psychol. Bull. 110 (3), 406e425.

Monroe, S.M., Reid, M.W., 2008. Gene-environment interactions in depression research: genetic polymorphisms and life-stress polyprocedures. Psychol. Sci. 19 (10), 947e956.

Montgomery, S.A., Åsberg, M.A., 1979. A new depression scale designed to be sensitive to change. Br. J. Psychiatry 134, 382e889.

Munafò, M.R., Durrant, C., Lewis, G., Flint, J., 2009. Gene × environment interactions at the serotonin transporter locus. Biol. Psychiatry 65 (3), 211e219.

Nevonen, L., Broberg, A.G., 2001. Validating the eating disorder inventory-2 (EDI-2) in Sweden. Eat. Weight Disord. 6, 59e67.

Norman, R.E., Byambaa, M., De, R., Butchart, A., Scott, J., Vos, T., 2012. The long-term health consequences of child physical abuse, emotional abuse, and neglect: a systematic-review and metaanalysis. PLos Med. 9 (11), e1001349.

Norring, C., Sohlberg, S., 1988. Eating disorders inventory in Sweden: description, cross-cultural comparison, and clinical utility. Acta Psychiatr. Scand. 78, 567e575.

Nugent, N.R., Tyrka, A.R., Carpenter, L.L., Price, L.H., 2011. Gene-environment interactions: early life stress and risk for depressive and anxiety disorders. Psychopharmacology 214, 175e196. 
Patton, J.H., Stanford, M.S., Barratt, E.S., 1995. Factor structure of the Barratt impulsiveness scale. J. Clin. Psychol. 51, 768e774.

Racine, S.E., Culbert, K.M., Larson, C.L., Klump, K.L., 2009. The possible influence of impulsivity and dietary restraint on associations between serotonin genes and binge eating. J. Psychiatric Res. 43, 1278e1286.

Richardson, J., Steiger, H., Schmitz, N., Joober, R., Bruce, K.R., Israel, M., Gauvin, L., Anestin, A.S., Dandurand, B.A., Howard, H., de Guzman, R., 2008. Relevance of the 5-HTTLPR polymorphism and childhood abuse to increased psychiatric comorbidity in women with bulimia-spectrum disorders. J. Clin. Psychiatry 69, 981e990.

Risch, N.J., Herrell, R., Lehner, T., Liang, K.Y., Eaves, L., Hoh, J., Griem, A., Kovacs, M., Ott, J., Merikangas, K.R., 2009. Interaction between the serotonin transporter gene (5-HTTLPR), stressful life events, and risk of depression. JAMA 301 (23), 2462e2471.

Rothman, K.J., 1976. Causes. Am. J. Epidemiol. 104 (6), 587e592. Rothman, K.J., Greenland, S., 1998. Modern Epidemiology. Lippencott-Raven, Philadelphia.

Scherag, S., Hebebrand, J., Hinney, A., 2010. Eating disorders: the current status of molecular genetic research. J. Eur. Child Adolesc. Psychiatry 19, $211 \mathrm{e} 226$.

Smolak, L., Murnen, S.K., 2002. A meta-analytic examination of the relationship between child sexual abuse and eating disorders. Int. J. Eat. Disord. 31, 136e150.

Solmi, M., Gallicchio, D., Collantoni, E., Correll, C.U., Clementi, M., Pinato, C., Forzan, M., Cassina, M., Fontana, F., Giannunzio, V., Piva, I., Siani, R., Salvo, P., Santonastaso, P., Tenconi, E., Veronese, N., Favaro, A., 2016. Serotonin transporter gene polymorphism in eating disorders: data from a new biobank and META-analysis of previous studies. World J. Biol. Psychiatry. http://dx.doi .org/10.3109/15622975.2015.1126675.

Steiger, H., Bruce, K.R., Gauvin, L., Groleau, P., Joober, R., Israel, M., Richardson, J., Kin, F.Y.N., 2011. Contributions of the glucocorticoid receptor polymorphism (Bcl1) and childhood abuse to risk of bulimia nervosa. Psychiatry Res. 187, 193e197.

Steiger, H., Gauvin, L., Joober, R., Israel, M., Badawi, G., Groleau, P., Bruce, K.R., Kin, Y.N., Sycz, L., Ouelette, A.S., 2012. Interaction of the Bcl1 glucocorticoid receptor polymorphism and childhood abuse in bulimia nervosa (BN): relationship to BN and to associated trait manifestations. J. Psychiatric Res. 46, 152e158.

Steiger, H., Joober, R., Israël, M., Young, S.N., Kin, N.Y., Kwong, N.M., Gauvin, L., Bruce, K.R., Joncas, J., Torkaman-Zehi, A., 2005. The 5HTTLPR polymorphism, psychopathologic symptoms, and platelet [3H-] paroxetine binding in bulimic syndromes. Int. J. Eat. Disord. 37 (1), 57e60.

Steiger, H., Richardson, J., Joober, R., Gauvin, L., Israel, M., Bruce, K.R., Kin, Y.N., Howard, H., Young, S.N., 2007. The 5-HTTLPR polymorphism, prior maltreatment and dramatic-erratic personality manifestations in women with bulimic syndromes. J. Psychiatry Neurosci. 32, 354e362.

Stoltenberg, S.F., Anderson, C., Nag, P., Anagnopoulos, C., 2012. Association between the serotonin transporter triallelic genotype and eating problems in moderated by the experience of childhood trauma in women. Int. J. Eat. Disord. 45, 492e500.

Svanborg, P., Åsberg, M., 2001. A comparison between the beck depression inventory (BDI) and the self-rating version of the Montgomery Åsberg depression rating scale (MADRS). J. Affect. Disord. $64,203 \mathrm{e} 216$.

Svanborg, P., Ekselius, L., 2003. Self-assessment of DSM-IV criteria for major depression in psychiatric out- and inpatients. Nordic J. Psychiatry 57, $291 \mathrm{e} 296$.

Tabachnick, B.G., Fidell, L.S., 2013. Using Multivariate Statistics, sixth ed. Pearson, Boston. 
Trace, S.E., Baker, J.H., Penas-Lledo, E., Bulik, C.M., 2013. The genetics of eating disorders. Annu. Rev. Clin. Psychol. 9, 589e620.

Uher, R., McGuffin, P., 2008. The moderation of the serotonin transporter gene of environmental adversity in the aetiology of mental illness: review and methodological analysis. Mol. Psychiatry 13, 131e146.

van Eekelen, A.M., Ellis, J.A., Pennell, C.E., Craig, J., Saffery, R., Mattes, E., Olsson, C.A., 2012. Stresssensitive neurosignalling in depression: an integrated network biology approach to candidate gene selection for genetic association analysis. Ment. Illn. 4 (21), 105e114.

van Strien, T., 2002. DEBQ, Dutch Eating Behavior Questionnaire Manual. Pearson, UK Thames Valley Test Company, Bury St. Edmunds, England/London.

van Strien, T., van der Zwaluw, C.S., Engels, R.C.M.E., 2010. Emotional eating in adolescents: a gene (SLC6A4/5-HTT) - depressive feelings interaction analysis. J. Psychiatric Res. 44, 1035e1042.

VanderWeele, T.J., Knol, M.J., 2014. A tutorial on interaction. Epidemiol. Methods 3 (1), 33e72.

von Ranson, K.M., Klump, K., Iacono, W.G., McGue, M., 2005. The Minnesota Eating Behavior Survey: a brief measure of disordered eating attitudes and behaviours. Eat. Behav. 6, 373e392.

Wang, T.Y., Lee, S.Y., Chen, S.L., Huang, S.Y., Chang, Y.H., Tzeng, N.S., Lu, R.B., 2013. Association between DRD2, 5-HTTLPR, and ALDH2 genes and specific personality traits in alcohol- and opiatedependent patients. Behav. Brain Res. 250, 285e292. 